\title{
The Relationship of Vitamin D Insufficiency with Low-Energy Fractures in Children
}

\author{
Majed Nasser Alosaimi*, Yousef Hussni Qari, Abdulaziz Abdulelah Abu Alnasr, Hani Ibrahim Barnawi, Abdullaziz \\ Mohammad Bazaid, Khalid Ayidh Alotaibi, Muhammad Anwar Khan \\ King Saud Bin Abdulaziz University for Health Sciences, King Abdullah International Medical Research Center, King Abdulaziz \\ Medical City WR, Jeddah, Saudi Arabia
}

Edited by: Ksenija Bogoeva-Kostovska Citation: Alosaimi MN, Qari YH, Alnasr AAA, Barnaw HI, Bazaid AM, Alotaibi KA, Khan MA. The Relationship of Vitamin D Insufficiency with Low-Energy Fractures in Children. Open Access Maced J Med Sci. 2020 Oct 19; https://doi.org/10.3889/oamims.2020.4752 Keywords: Vitamin D; Low-energy fractures; Pediatric

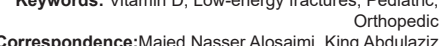
Medical City -Jeddah, King Khalid National Guard Hospital. King Saud Bin Abdulaziz University for Health E-mailosiming .osaimima@ngha.med.sa Received: 08-Apr-2020 Revised: 05-Oct-2020

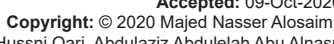
Hani lbrahim Barnawi Abdullaziz Mohammad Bazaid, Khalid Ayidh Alotaibi, Muhammad Anwar Khan Funding: This research did not receive any financial Competing Interests: The authors have declared that no Open Access: This is an open-access article distributed under the terms of the Creative Commons Attribution-

\begin{abstract}
BACKGROUND: Approximately $50 \%$ of the world population are suffering from Vitamin D insufficiency. Vitamin D is one of the steroid hormones, which is a fat soluble vitamin that has a critical role in maintaining the homeostasis of bones. Low-energy fractures are defined as falling from the level of standing height or even less that usually should not result in fractures. Another study that was done in Jeddah on a sample of 510 children between the age of 4-15 taken in the pediatric clinic at Jeddah Clinic Hospital-Kandarah. 59\% had relative deficiency, and $27 \%$ had a deficiency in 25 -hydroxyvitamin $D$.
\end{abstract}

AIM: Therefore, this research is conducted to collect more evidences to assess the association between vitamin D level and low-energy fractures in children.

METHODS: The study group consisted of 14 children aged 3-15 years old with low-energy fractures and the contro group consisted of 24 children in the same age without fractures. Vitamin D level was measured in each one of them and X-ray was obtained from the cases to prove the presence of low-energy fracture. The analysis plan that was used in this research is Fisher's exact test to overcome the small sample size.

RESULTS: Vitamin D levels were found deficient in four cases, and eight of them were insufficient. Whereas, the normal level of Vitamin D was found in only two of the cases. On the other hand, in the control group the level of Vitamin $D$ was deficient in four participants, and 15 others were found to be insufficient. Also, five of the participants were found to have a normal Vitamin D level. According to the results, low levels of Vitamin D were observed in both groups. A total of 23 out of 38 children enrolled in the study were found to have an insufficient Vitamin D level. The result of $p=0.718$ which is not significant to prove the correlation between Vitamin D insufficiency and low-energy fractures.

CONCLUSION: In conclusion, this study did not show any relation between Vitamin D level and the presence of low energy fracture. Future studies are required to include more subjects and centers to their study or to compare the low energy fracture and high energy fracture in term of Vitamin D level.

\section{Introduction}

Approximately $50 \%$ of the world population are suffering from Vitamin D insufficiency. In addition, there are one billion people across the world among various races and ages who were estimated to have Vitamin $D$ deficiency [1]. Vitamin D is one of the steroid hormones, which is a fat soluble vitamin that has a critical role in maintaining the homeostasis of bones [2], [3]. Vitamin D have two forms that are physiologically active [3]. One is D2 that is also called ergocalciferol which can be found in the diet of vegetarian origin [2], [3]. The other type is D3, known as cholecalciferol, which is produced in human from 7-dehydrocholecalciferol subcutaneously by ultraviolet light $B$ that is considered 3 times more effective than D2 [2,3]. Both Vitamins D2 and D3 are first hydroxylated in the liver to form 25 hydroxy Vitamin $D$, and then in response to the level of parathyroid hormone (PTH), it is hydroxylated in the kidneys to 1,25 dihydroxyl Vitamin D [3]. People vary in their ability to produce it endogenously through the exposure to sunlight [4]. The amount of Vitamin $D$ that human can get from the sunlight depends on the day time and the amount of melanin pigment in the skin, thus 3-5 times longer exposure to the sun light is required by darker skin people to obtain the same amount of Vitamin D [1]. The prevalence of Vitamin $\mathrm{D}$ insufficiency in the general population is quite high: $42.5 \%$ in France, around $35-70 \%$ in Europe and $36 \%$ in the US [5]. On the other hand, $92 \%$ of Arab children with rickets and $97 \%$ of their mothers have been found recently as Vitamin D deficient [3]. A study showed that a maternal Vitamin D insufficiency during pregnancy was associated with increasing the risk fractures in children [6]. Another study that was done in Jeddah on a sample of 510 children between the age of 4-15 taken in the pediatric clinic at Jeddah Clinic HospitalKandarah. $59 \%$ had relative deficiency, and $27 \%$ had a deficiency in 25-hydroxyvitamin D (25(OH)D) [4]. Its deficiency may cause a number of diseases as many studies indicated, for example, fractures, secondary hyperparathyroidism, diminished response 
to antiresorptives, rickets/osteomalacia, autoimmune diseases, and hypocalcemia [7].

Low-energy fractures are defined as falling from the level of standing height or even less that usually should not result in fractures [8]. In one of the studies that has been conducted in Qatar has found that the history of fractures is prevalent in children with rickets up to $22.5 \%$ more than children with normal calcium range [9]. A recent study found that, the level of Vitamin $D$ in children with chronic kidney disease, which is a known disease with low level of Vitamin D, and children with fracture is the same. According to that, they suggest that fracture patients are more likely to be Vitamin D deficient than previously thought [10].

Many studies have been conducted regarding low serum 25(OH)D. However, one of the researches concluded the fact that adequate evidence to prove the association between low serum $25(\mathrm{OH}) \mathrm{D}$ and a rise in the risk of fractures in children are absent. Additionally, the same study states that various researches suggest an increase in the number of children presenting with symptomatic Vitamin D deficiency, yet without reporting of the current incidence rate [9]. Another study used the historical criteria of categorizing Vitamin D level ( $<11 \mathrm{ng} /$ $\mathrm{mL}$ is deficient, between 11 and $20 \mathrm{ng} / \mathrm{mL}$ is insufficient, and more than $20 \mathrm{ng} / \mathrm{mL}$ is sufficient) to classify the children with fractures based on it, while they suggested that they should have used the biological criteria ( $<20 \mathrm{ng} /$ $\mathrm{mL}$ is deficient, between 20 and $32 \mathrm{ng} / \mathrm{mL}$ is insufficient, and more than $32 \mathrm{ng} / \mathrm{mL}$ is sufficient) [4].

Therefore, this research is conducted to collect more evidences to assess the association between Vitamin D level and low-energy fractures in children and to increase the understanding of the relationship between Vitamin D level and low-energy fractures, which eventually aims to enhance the awareness of Vitamin D importance in the community of Saudi Arabia. As well as, the research seeks to contribute to the available reports of Vitamin D insufficiency in the pediatric population of Saudi Arabia.

\section{Methodology}

The study was conducted in the national guard hospital's emergency department and trauma clinics. The study included both genders between 3 and 15 years old children who have a low - energy fracture, while the study excluded the children with chronic renal disease and high energy fracture such as fractures caused by road traffic accidents. The research was conducted by case control design. The research included 14 subjects in the case group and 24 subjects in the control group. The study sample was collected through convenience sampling technique which was started after attaining the ethical approval October 2017 until February 2019. The method of collecting the required data utilized $X$-ray to prove the presence of the low-energy fracture and the Vitamin $D$ level test to categorize the patient's Vitamin D level into deficiency (<25 nmol/L), insufficiency (25-49 nmol/L), and normal (50-125 nmol/L) to find if the patient with lowenergy fracture has insufficient Vitamin $D$ level or not. Finally, the analysis plan that was used in this research is Fisher's exact test to overcome the small sample size.

\section{Results}

Analysis of the study is done based on the available data that were collected. A total of 38 children, regardless of age and gender differences, were enrolled in the study 14 cases and 24 controls (Table 1).

Table 1: Total sample size with representation of enrolled patients in each Vitamin D level group, regardless of the presence of low-energy fractures. $n=$ number of patients tested for Vitamin D

\begin{tabular}{lll}
\hline Presence of fracture and vitamin D level categories & $\mathrm{n}$ & $\%$ \\
\hline Low energy fracture & & \\
Yes & 14 & 36.8 \\
No & 24 & 63.2 \\
Vitamin D level & & \\
Deficiency & 8 & 21.1 \\
Insufficiency & 23 & 60.5 \\
Normal & 7 & 18.4 \\
Total & 38 & 100 \\
\hline
\end{tabular}

The mean age in the case group was $9.7 \pm 2.9$ and their mean Vitamin D level was $36.3 \pm 13.2$. In contrast, the mean age of the control group was $8.1 \pm 3.3$ and their mean Vitamin D level was $40.1 \pm 19.6$

Vitamin $D$ levels were found deficient in four cases, and eight of them were insufficient. Whereas, the normal level of Vitamin D was found in only two of the cases. On the other hand, in the control group the level of Vitamin D was deficient in four participants, and 15 others were found to be insufficient. Also, five of the participants were found to have a normal Vitamin D level (Table 2).

Table 2: Description of patients with or without low-energy fractures and categorizing them into each Vitamin D level group with percentages. $p$-value is based on analysis of data using Fisher exact test. $\mathbf{n}=$ number of patients tested for Vitamin $\mathbf{D}$

\begin{tabular}{|c|c|c|c|c|}
\hline \multirow{2}{*}{$\begin{array}{l}\text { Frequency of various } \\
\text { vitamin D level } \\
\text { Vitamin D grade }\end{array}$} & \multicolumn{2}{|c|}{ Low energy fracture } & \multirow[t]{2}{*}{ Total n (\%) } & \multirow[t]{2}{*}{$p$-value } \\
\hline & Yes n (\%) & No n (\%) & & \\
\hline Deficiency & $4(28.6)$ & $4(16.7)$ & $8(21.1)$ & \\
\hline Insufficiency & $8(57.1)$ & $15(62.5)$ & $23(60.5)$ & $0.718^{*}$ \\
\hline Normal & $2(14.3)$ & $5(20.8)$ & $7(18.4)$ & \\
\hline Total & $14(100)$ & $24(100)$ & $38(100)$ & \\
\hline
\end{tabular}

According to the results, low levels of vitamin D were observed in both groups. A total of 23 out of 38 children enrolled in the study were found to have an insufficient Vitamin D level.

The data were analyzed and represented through fissure exact test. The result of $p=0.718$ which is not significant to prove the correlation between Vitamin $\mathrm{D}$ insufficiency and low-energy fractures (Table 2). 


\section{Discussion}

In this case control study, we compared the level of Vitamin D of children with and without low energy fractures, which showed that level of Vitamin D in the involved participants has not implicated any correlation between Vitamin $D$ level and the presence or absence of low energy fractures. Most of the participants had insufficient Vitamin D level, regardless of having a low energy fracture.

There are two studies that compared the level of Vitamin $D$ in children with fractures and children without fractures $[10,11]$. The first one is a case control study that involved 100 children as cases of low energy fracture and 127 children as a control group without fractures, concluded that less susceptibility for fractures by 1.06 folds is achieved through maintaining higher levels of Vitamin D [11]. In the other study, which was a comparative cohort, 58 children with acute low energy fracture were compared to 103 children with chronic kidney disease [10]. They have found that the level of Vitamin $D$ in the low energy fracture group was similar to those with chronic kidney disease [10].

Some limitations were encountered during the conduction of this research. One of which is the sample size. Larger sample size was desired at the beginning of the study, which could not be fulfilled due to location of the center, limited people who can be treated in the center, and number of centers that had been involved. In order to overcome this limitation, some measures were taken. The age limit of children to be enrolled in the study was extended from 3 to 12 years of age to 3-15 years. Another obstacle was the lack of cooperation from the patients and their custodians as some of them were afraid to do the blood test. Moreover, it was not applicable to obtain blood samples from patients in the emergency department because of the overload on the emergency department lab. The impact of this problem was reduced because most of the patients who come to the emergency department are referred to the trauma clinic, where they have been included in the study.

Despite these limitations, the study stands out as the first paper to compare low energy fractures with Vitamin D insufficiency in the kingdom of Saudi Arabia as far as we know. Furthermore, the study offered patients the choice to ask for Vitamin D supplements in case it was low. Awareness campaign is a possible future implementation due to the importance of this issue in the community of Saudi Arabia.

\section{Conclusion}

In conclusion, this study did not show any relation between vitamin $\mathrm{D}$ level and the presence of low energy fracture. Future studies are required to include more subjects and centers to their study or to compare the low energy fracture and high energy fracture in term of Vitamin D level.

\section{References}

1. Nair R, Maseeh A. Vitamin D: The sunshine vitamin. J Pharmaco Pharmacother. 2012;3(2):118-26.

PMid:22629085

2. Kennel KA, Drake MT, Hurley DL. Vitamin D Deficiency in adults: When to test and how to treat. Mayo Clin Proc. 2010;85(8):752-8. https://doi.org/10.4065/mcp.2010.0138 PMid:20675513

3. De-Regil LM, Palacios C, Ansary A, Kulier R, Peña-Rosas JP. Vitamin $D$ supplementation for women during pregnancy. Cochrane Database Syst Rev. 2012;1:CD008873. https://doi. org/10.1002/14651858.cd008873.pub2 PMid:26765344

4. Mansour MM, Alhadidi KM. Vitamin D deficiency in children living in Jeddah, Saudi Arabia. Indian J Endocrinol Metab. 2012;16(2):263-9. https://doi.org/10.4103/2230-8210.93746 PMid:22470865

5. Deschasaux M, Souberbielle JC, Partula V, Lécuyer L, Gonzalez R, Srour B. et al. What do people know and believe about Vitamin D? Nutrients. 2016;8(11):718. https://doi. org/10.3390/nu8110718

PMid:27845705

6. Wacker M, Holick MF. Vitamin D-effects on skeletal and extraskeletal health and the need for supplementation. Nutrients. 2013;5(1):111-48. https://doi.org/10.3390/nu5010111 PMid:23306192

7. Okazaki R, Ozono K, Fukumoto S, Inoue D, Yamauchi M, Minagawa $\mathrm{M}$, et al. Assessment criteria for vitamin $\mathrm{D}$ deficiencyl insufficiency in Japan: Proposal by an expert panel supported by the research program of intractable diseases, ministry of health, labour and welfare, Japan, the Japanese society for bone and mineral research and the Japan endocrine society. J Bone Miner Metab. 2016;35(1):1-5. https://doi.org/10.1007/s00774-016-0805-4 PMid:27882481

8. Holmberg AH. Risk Faktors for Fracture in Middle-aged Men and Women. Malmö: Clinical and Molecular Osteoporosis Research Unit, Clinical Sciences; 2006. p. 103. Available from: https:// www.portal.research.lu.se/portal/en/publications/risk-faktorsfor-fracture-in-middleaged-men-and-women(3fa2dbaf-92594207-875b-7b16808a7562)/export.html\#export. [Last accessed on 2017 Apr 12].

9. Moon RJ, Harvey NC, Davies JH, Cooper C. Vitamin D and skeletal health in infancy and childhood. Osteoporos Int. 2014;25(12):2673-84. https://doi.org/10.1007/s00198-014-2783-5 PMid:25138259

10. Peter D, Christopher J, Son H, Ryan C, Lisa S, Shevaun M. Low vitamin $D$ levels in children with fractures: A comparative cohort study. HSS J. 2015;11(3):249-57.

PMid:26981060

11. Karpiński M, Galicka A, Milewski R, Popko J, Badmaev V, Stohs S. Association between Vitamin D receptor polymorphism and serum Vitamin D levels in children with low-energy fractures. J Am Coll Nutr. 2017;36(1):64-71. https://doi.org/10.1080/07315 724.2016.1218803

PMid:28067591 